Historic, Archive Document

Do not assume content reflects current scientific knowledge, policies, or practices. 


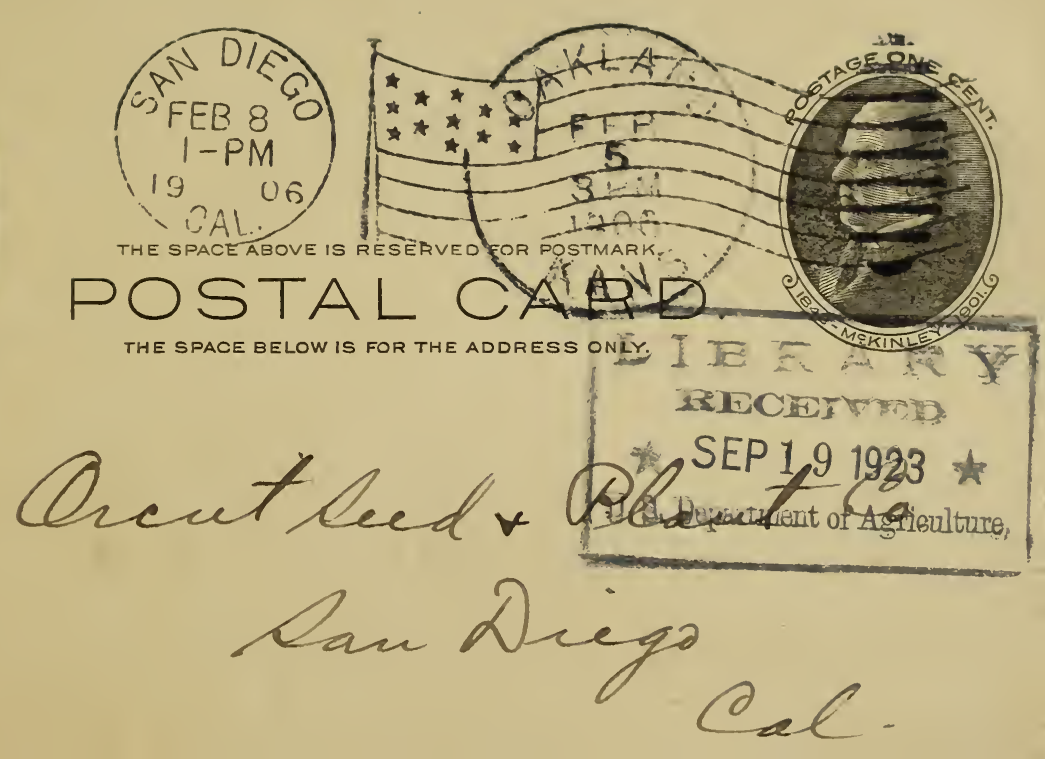




\section{APPLE SEEDLINGS.}

No. 1, 3-16 and up, straight roots, at $\$ 2.00$ per MI No. 1, 3-16 and up, branched roots, at 1.75 per MI No. 2, 2-16 to 3-16, straight roots, at .80 per MI No. 3, a good grade, - _ _ $\quad .35$ per MI A good grade of grafters, - _ _ $\quad .40$ per MI

\section{IMPORTED S TOCKS.}

\section{French Mahaleb.}

3 to 5 M. M., at - $\quad$ - $\$ 3.00$ per M

\section{French Pear.}

5 to 7 M. M., branched roots, at $\quad \$ 5.50$ per $\mathrm{MI}$

\section{Myrabolan Plum.}

5 to 7 M. M., at

We are making these low prices to clean up. The stock was grown on new ground and is clean and healthy. We guarantee our grades. Order by return mail. Can ship at any time.

SHAWNEE NURSERY CO., Topeka, Kansas. 